\title{
Estimation of genetic parameters and detection of quantitative trait loci for minerals in Danish Holstein and Danish Jersey milk
}

\author{
Bart Buitenhuis ${ }^{1 *}$, Nina A Poulsen², Lotte B Larsen² and Jakob Sehested ${ }^{3}$
}

\begin{abstract}
Background: Bovine milk provides important minerals, essential for human nutrition and dairy product quality. For changing the mineral composition of the milk to improve dietary needs in human nutrition and technological properties of milk, a thorough understanding of the genetics underlying milk mineral contents is important. Therefore the aim of this study was to 1) estimate the genetic parameters for individual minerals in Danish Holstein (DH) $(n=371)$ and Danish Jersey (DJ) ( $n=321)$ milk, and 2) detect genomic regions associated with mineral content in the milk using a genome-wide association study (GWAS) approach.

Results: For DH, high heritabilities were found for $\mathrm{Ca}(0.72)$, Zn (0.49), and P (0.46), while for DJ, high heritabilities were found for $\mathrm{Ca}(0.63)$, Zn (0.57), and Mg (0.57). Furthermore, intermediate heritabilities were found for $\mathrm{Cu}$ in $\mathrm{DH}$, and for $\mathrm{K}$, $\mathrm{Na}$, P and Se in the DJ. The GWAS revealed a total of 649 significant SNP markers detected for Ca (24), Cu (90), Fe (111), $\mathrm{Mn}$ (3), $\mathrm{Na}$ (1), $\mathrm{P}$ (4), Se (12) and $\mathrm{Zn}$ (404) in DH, while for DJ, a total of 787 significant SNP markers were detected for $\mathrm{Ca}$ (44), Fe (43), K (498), Na (4), Mg (1), P (94) and Zn (3). Comparing the list of significant markers between DH and DJ revealed that the SNP ARS-BFGL-NGS-4939 was common in both breeds for Zn. This SNP marker is closely linked to the DGAT1 gene. Even though we found significant SNP markers on BTA14 in both DH and DJ for Ca, and Fe these significant SNPs did not overlap.
\end{abstract}

Conclusion: The results show that $\mathrm{Ca}, \mathrm{Zn}, \mathrm{P}$ and Mg show high heritabilities. In combination with the GWAS results this opens up possibilities to select for specific minerals in bovine milk.

Keywords: Bovine milk, Minerals, Element, Genetic parameters, Association study

\section{Background}

Bovine milk provides essential substances for growth and development of the newborn. Besides water, milk consists of proteins, fat, lactose, vitamins and minerals, in addition to other components like metabolites and free oligosaccharides. The mineral fraction constitutes a minor fraction of the milk solids (approximately 7.1 to $7.4 \mathrm{~g} / \mathrm{L}$ ), and comprises cations (among others calcium $(\mathrm{Ca})$, magnesium $(\mathrm{Mg})$, sodium $(\mathrm{Na})$ and potassium $(\mathrm{K}))$, and anions (among others phosphorus, and chloride) $[1,2]$. Minerals contribute to important physiological processes and in human nutrition it has been shown that

\footnotetext{
*Correspondence: bart.buitenhuis@mbg.au.dk

'Aarhus University, Center for Quantitative Genetics and Genomics, Department of Molecular Biology and Genetics, Blichers Allé 20, P.O. Box 50 DK-8830 Tjele, Denmark

Full list of author information is available at the end of the article
}

e.g. Ca and P play a role in bone metabolism, Se and $\mathrm{Zn}$ play a role in the immune system while $\mathrm{Ca}, \mathrm{K}$ and $\mathrm{Mg}$ are involved in maintaining blood pressure [3-5]. High mineral content and availability of milk makes dairy products important sources of minerals to the human diet $[6,7]$.

Furthermore, the mineral composition of milk is important for the technological properties of milk, because minerals are involved in the structure and stability of casein micelles (micellar bound) and thereby e.g. the coagulation properties of the milk. Free divalent cations, especially $\mathrm{Ca}$ ions in milk serum, significantly influence the surrounding environment of the negatively charged casein micelles [8] and thereby the coagulation properties of the milk.

For changing the mineral composition of milk to improve dietary needs in human nutrition or to improve 
technological properties of milk, two different strategies can be employed: Fortification or increasing the natural content. As fortification by e.g. Ca is problematic for different reasons, including changing the milk $\mathrm{pH}$ and stability [9] a good understanding of the genetics underlying milk mineral content is needed in relation to explore the possibilities for increasing mineral content through feeding or breeding. It has been shown that the mineral content in bovine milk is influenced by non-genetic factors like lactation stage and nutrition $[3,10]$. However, substantial genetic variation for a number of minerals in bovine milk has been reported [11]. In the current study we have collected tissue and milk samples from Danish Holstein and Danish Jersey dairy cows. The tissue samples were examined using the bovine $777 \mathrm{k}$ single nucleotide polymorphism (SNP) chip combined with detailed milk mineral profiling by inductively coupled plasma mass spectrometry (ICP-MS). The aim of this study was to 1) estimate the genetic parameters for individual minerals in Danish Holstein (DH) and Danish Jersey (DJ) dairy milk, and 2) detect genomic regions associated with mineral content in the milk using a genome-wide association study (GWAS) approach.

\section{Methods}

\section{Animals}

All procedures were performed in accordance with the National Guidelines for Animal Experimentation and the guidelines of the Danish Animal Experimental Ethics Committee. Within the Danish-Swedish Milk Genomics Initiative, morning milk samples were collected from 456 DH cows (20 dairy herds, October - December 2009) and 436 DJ (22 dairy herds, February - April 2010). From each herd, between 19 and 24 cows were sampled. All cows were housed in loose housing systems, fed according to standard practice, and milked twice a day. The cows sampled were all in mid-lactation (d129 to d229 in DH and d130 to d252 in DJ) and within parity 1 to 3 . Immediately after milking, milk samples were placed on ice for transport to the laboratory. Once at the laboratory, the milk samples were treated as described by Poulsen et al. [12].

\section{Micro and macro elements}

Ten different elements $(\mathrm{Ca}, \mathrm{Cu}, \mathrm{Fe}, \mathrm{K}, \mathrm{Mg}, \mathrm{Mn}, \mathrm{Na}, \mathrm{P}, \mathrm{Se}$, and $\mathrm{Zn}$ ) were extracted from skimmed milk by acid sonication and identified using inductively coupled plasma mass spectrometry (ICP-MS) as described by Cava-Montesinos et al. [13].

References and standards were analyzed in parallel with the skimmed milk samples. The reference was whole milk powder 1549a from The National Institute of Standards and Technology (NIST, U.S. Department of Commerce). For $\mathrm{Ca}, \mathrm{Mg}, \mathrm{P}, \mathrm{S}, \mathrm{Na}$ and $\mathrm{K}$ the standard CZ9097 Mix 017 from the Czeck Metrology Institute (Analytika Ltd., Praque, Czeck Republic) was used. For $\mathrm{Cu}, \mathrm{Fe}, \mathrm{Mn}, \mathrm{Se}$, and $\mathrm{Zn}$, the standard PlasmaCAL custom standard from SCP Science, Canada, was used.

Samples were heated to $40^{\circ} \mathrm{C}$ in a water bath. Two g of each milk sample was diluted with $2 \mathrm{~mL}$ aqua regia $(65 \%$ super pure nitric acid and 30\% super pure hydrochloric acid) in $13 \mathrm{~mL}$ polystyrene tubes (Deltalab, Spain), shaken for a few seconds on Whirl-mixer and left until next day. Samples were then ultrasonicated (Branson 3510, Danbury, USA) for 10 minutes and diluted to $10 \mathrm{~mL}$ by $2 \%$ super-pure nitric acid, and ultrasonicated for another 10 minutes before centrifugation at $3,578 g$ for 2 minutes. The supernatant $(5 \mathrm{~mL})$ was transferred to new vials $13 \mathrm{~mL}$ polystyrene tubes (Deltalab, Spain) and analyzed by ICP-MS (X-series II) from Thermo Fisher Scientific Inc., U.S.

\section{SNP chip and genotyping}

The genotyping procedure was carried out as described earlier [14]. In short, $371 \mathrm{DH}$ and $321 \mathrm{DJ}$ cows were genotyped with the bovineHD beadchip [15]. The bovineHD chip contains 777,962 markers with a median interval of $2.68 \mathrm{~kb}$ between SNPs (www.illumina.com/documents/ products/datasheets/datasheet_bovineHD.pdf). Genomic DNA was extracted from ear tissue. The platform used was an Illumina Infinium II Multisample assay device. SNP chips were scanned using iScan and analyzed using Beadstudio version 3.1 software. The quality parameters used for the selection of SNPs in the GWAS were minimum call rates of $80 \%$ for individuals and $95 \%$ for loci. Marker loci with minor allele frequencies (MAFs) below $1 \%$ were excluded. The quality of the markers was assessed using the GenCall data analysis software of Illumina. Individuals with average GenCall scores below 0.65 were excluded following Teo et al. [16]. The SNP positions were based on the Bos taurus genome assembly (Btau_4.0) [17]. In total 494,984 SNP markers were used in both DH and DJ.

\section{SNPs assigned to genes}

For each gene known in the cattle database, location in the bovine genome was determined as $5 \mathrm{~Kb}$ before the start position of the first exon to $5 \mathrm{~Kb}$ after the end position of the last exon. Hence, the defined gene region includes all introns and parts of the upstream and downstream regions of the gene. When a SNP was located in this region it was assigned to the corresponding gene.

\section{Statistical analysis}

The statistical analysis was based on the $315 \mathrm{DH}$ and 316 DJ animals having both genotypic and phenotypic records.

\section{Calculation of the G-matrix}

The calculation of the genomic relationship matrix has been described in detail by Buitenhuis et al. [14]. In short, the 
genomic relationship matrix was calculated for each breed separately. For each chromosome, a genomic relationship matrix as described by the first method presented in VanRaden [18] was calculated as follows: Let $\mathbf{M}$ be a matrix with dimensions of the number of individuals $(n)$ by the number of loci $(m)$ that specifies which marker alleles each individual inherited. The elements of $\mathbf{M}$ were set to $-1,0,1$ for the homozygote, heterozygote and the other homozygote, respectively. The diagonals of $\mathbf{M}^{\prime} \mathbf{M}$ counts the number of homozygous loci for each individual and off diagonals measure the number of alleles shared by relatives. Let the frequency of the second allele at locus $i$ be $p_{i}$, and let $\mathbf{P}$ contain the allele frequencies, such that column $i$ of $\mathbf{P}$ equals $2\left(p_{i}-0.5\right)$. Subtraction of $\mathbf{P}$ from $\mathbf{M}$ gives $\mathbf{Z}$, which is needed to set the expected mean value to 0 . The genomic relationship matrix $\mathbf{G}$ was then calculated as $\mathbf{Z Z}^{\prime} /\left[2 \sum \mathrm{p}_{\mathrm{i}}\left(1-\mathrm{p}_{\mathrm{i}}\right)\right][18]$.

\section{Estimation of heritability}

To estimate the genetic parameters and variance components the REML approach in DMU was used [19]. The following model was used in the analysis:

$$
\begin{aligned}
\mathrm{Y}_{\mathrm{ijkl}} & =\mu+\operatorname{herd}_{\mathrm{i}}+\text { parity }_{\mathrm{j}}+\mathrm{b}_{1} \times \operatorname{DIM}_{\mathrm{k}} \\
& +\operatorname{animal}_{1}+\mathrm{e}_{\mathrm{ijkl}}
\end{aligned}
$$

Where $Y_{\mathrm{ijkl}}$ is the phenotype of individual $l$ in herd $\mathrm{i}$ and lactation $\mathrm{j}, \mu$ is the fixed mean effect, herd $\mathrm{d}_{\mathrm{i}}$ is a fixed effect $(i=1,2, \ldots, 19 \mathrm{DH} ; \mathrm{i}=1,2, \ldots, 22 \mathrm{DJ})$, parity $\mathrm{i}_{\mathrm{j}}$ a fixed effect ( $j=1,2,3 \mathrm{DH}, \mathrm{j}=1,2,3 \mathrm{DJ}), \mathrm{b}_{1}$ is the regression coefficient for DIM $_{k}$, DIM $k$ is a covariate of days in milk (d129 to d229 in DH, d130 to d252 in DJ), and animal is the random additive genetic effect based on $\mathbf{G}$ of animal 1 [20].

The milk samples were taken once on each farm in a short period while the cows were housed inside, therefore we did not fit a season effect in the model.

Univariate analyses were performed to estimate the heritability, which was defined as:

$$
\mathrm{h}^{2}=\sigma_{\mathrm{a}}^{2} /\left(\sigma_{\mathrm{a}}^{2}+\sigma_{\mathrm{e}}^{2}\right)
$$

where $\sigma_{\mathrm{a}}^{2}$ was the genetic variation, and $\sigma_{\mathrm{e}}^{2}$ was the residual variation.

\section{Association mapping}

The association analysis was performed using the following linear model for each breed separately:

$$
\begin{aligned}
\mathrm{Y}_{\mathrm{ijklm}} & =\mu+\text { herd }_{\mathrm{i}}+\text { parity }_{\mathrm{j}}+\mathrm{b}_{1} \times \mathrm{DIM}_{\mathrm{k}}+\mathrm{b}_{2} \\
& \times \mathrm{SNP}_{\mathrm{m}}+\text { animal }_{1}+\mathrm{e}_{\mathrm{ijkl}} \mathrm{km}
\end{aligned}
$$

Where $Y_{\mathrm{ijklm}}$ is the phenotype of individual 1 in herd $\mathrm{i}$ and lactation $j, \mu$ is the fixed mean effect, herd $\mathrm{i}_{\mathrm{i}}$ is a fixed effect $(i=1,2, \ldots, 19 \mathrm{DH} ; \mathrm{i}=1,2, \ldots, 22 \mathrm{DJ})$, parity is a fixed effect $(j=1,2,3 \mathrm{DH}, j=1,2,3 \mathrm{DJ}), \mathrm{b}_{1}$ is the regression coefficient for $\mathrm{DIM}_{\mathrm{k}}$, DIM $\mathrm{k}$ is a covariate of days in milk (d129 to d229 in DH, d130 to d252 in DJ), $b_{2}$ is the allele substitution effect, $\mathrm{SNP}_{\mathrm{m}}$ is a covariate indicating if a SNP is homozygote $(0,2)$ or heterozygote $(1)$, and animal is the random additive genetic effect based on $\mathbf{G}$ of animal 1 [20]. The effect of the SNP was tested by a Wald test with a null hypothesis of $\mathrm{H}_{0}: \mathrm{b}=0$. The analyses were performed using REML in the R interface of DMU [19] (available at http://dmu.agrsci.dk). Significance thresholds were determined using a false discovery rate (FDR) correction using the $\mathrm{R}$ package "qvalue" version 1.34.0. A FDR of $\mathrm{P}<0.10$ was considered significant.

\section{Linkage disequilibrium}

The LD block around the most significant marker in a QTL was determined using HAPLOVIEW [21].

\section{Results}

In Table 1, the phenotypic mean, standard deviations and $\mathrm{CVs}$ for the minerals in the milk of DH and DJ are given. In general, $\mathrm{DH}$ has a lower mineral content $(\mathrm{Ca}, \mathrm{Cu}, \mathrm{Fe}$, $\mathrm{Mg}, \mathrm{Mn}, \mathrm{Na}, \mathrm{P}, \mathrm{Se}$, and $\mathrm{Zn}$ ) in the milk compared to DJ, except for $\mathrm{K}$ which is higher in the $\mathrm{DH}$ (1469.8 ppm \pm 115.0 DH vs. $1319.0 \mathrm{ppm} \pm 104.9 \mathrm{DJ})$. The mean levels of minerals in DH milk were in the range of $0.007 \mathrm{ppm}$ for Se to $1469.8 \mathrm{ppm}$ for $\mathrm{K}$, whereas the range for minerals in DJ milk was from $1468.8 \mathrm{ppm}$ for Ca to $0.01 \mathrm{ppm}$ for Se. The CVs were in the range of $7.8 \%$ for $\mathrm{K}$ to $33.3 \%$ for $\mathrm{Cu}$ in $\mathrm{DH}$, and $7.9 \%$ for $\mathrm{K}$ to $40.0 \%$ for $\mathrm{Cu}$ in $\mathrm{DJ}$.

Phenotypic correlations between the mineral and overall milk composition show similarity in both the $\mathrm{DH}$ as well as the DJ (Additional file 1: Table S1). Especially P, Ca and $\mathrm{Mg}$ were positively correlated and further showed a strong correlation to protein content. In cases there are differences in the sign of the correlation, these correlations are

\begin{tabular}{|c|c|c|c|c|c|c|}
\hline \multirow[t]{2}{*}{ Trait } & \multicolumn{3}{|c|}{ Danish Holstein } & \multicolumn{3}{|c|}{ Danish Jersey } \\
\hline & Mean $^{1}$ & SD & CV (\%) & Mean $^{1}$ & SD & CV (\%) \\
\hline $\mathrm{Ca}$ & 1214.2 & 123 & 10.1 & 1465 & 148 & 10.1 \\
\hline K & 1470 & 115 & 7.8 & 1319 & 105 & 7.9 \\
\hline $\mathrm{Na}$ & 349 & 74 & 21.1 & 389 & 101 & 25.9 \\
\hline$P$ & 725 & 78 & 10.8 & 880 & 93 & 10.6 \\
\hline $\mathrm{Mg}$ & 108 & 11 & 9.9 & 124 & 13 & 10.3 \\
\hline $\mathrm{Cu}$ & 0.03 & 0.01 & 33.3 & 0.05 & 0.02 & 40.0 \\
\hline $\mathrm{Fe}$ & 0.17 & 0.04 & 23.5 & 0.19 & 0.05 & 26.3 \\
\hline $\mathrm{Mn}$ & 0.02 & 0.005 & 25.0 & 0.03 & 0.009 & 30.0 \\
\hline $\mathrm{Se}$ & 0.007 & 0.002 & 28.6 & 0.01 & 0.002 & 20.0 \\
\hline $\mathrm{Zn}$ & 3.39 & 0.63 & 11.5 & 4.73 & 0.79 & 16.7 \\
\hline
\end{tabular}
not significant, i.e. the standard error is much larger compared to the estimate. However there is one exception:

Table 1 Mean (ppm) and standard deviation of micro and macro elements in Danish Holstein and Danish Jersey milk

${ }^{1}$ the mean of all micro and macro elements for the Danish Holstein differ significantly $(P<0.001)$ from the Danish Jersey. 
Lactose and $\mathrm{K}$ has a negative correlation $(-0.22 \pm 0.06)$ in the $\mathrm{DH}$, while these components have a positive correlation $(0.17 \pm 0.06)$ in DJ (Additional file 1: Table S1).

The heritability estimates and the genetic variance for the minerals for both DH and DJ are presented in Table 2. For DH, high heritabilities were found for $\mathrm{Ca}(0.72), \mathrm{Zn}$ (0.49), and $\mathrm{P}(0.46)$. For DJ, high heritabilities were found for $\mathrm{Ca}(0.63), \mathrm{Zn}(0.57)$, and $\mathrm{Mg}$ (0.57). Intermediate heritabilities were found for $\mathrm{Cu}$ in $\mathrm{DH}$, and for $\mathrm{K}, \mathrm{Na}, \mathrm{P}$ and Se in the DJ (Table 2).

\section{GWAS results}

The results of the GWAS are presented in Additional file 1: Table S1 for DH and Additional file 2: Table S2 for DJ including the allele-substitution effect, location and annotation.

\section{Danish Holstein}

In total 649 significant SNP markers were detected for $\mathrm{Ca}$ (24), $\mathrm{Cu}$ (90), Fe (111), Mn (3), Na (1), P (4), Se (12) and $\mathrm{Zn}$ (404) (Additional file 2: Table S2).

For $\mathrm{Ca}$ SNP markers were detected on BTA14. For $\mathrm{Cu}$ the QTL were distributed over 12 different chromosomes: BTA3 (6), BTA5 (26), BTA7 (25) and BTA14 (18) harbored most significant SNP markers. For Se 12 significant SNP markers were located on BTA8. All these 12 SNP markers were located in the same LD block (BOVINEHD0800024680-BOVINE0800024709) and assigned to chromosome 8 open reading frame, human C9orf3 (C8H9orf3) in the range of $82,922,191-82,965,051 \mathrm{bp}$ (BOVINEHD0800024693 - BOVINEHD0800024709). For $\mathrm{Zn}$ a strong QTL peak was detected on BTA2, where the most significant SNP marker (BOVINEHD0200037025) with a $-\log _{10}$ (P-value) of 12.69 was assigned to PDLIM1 interacting kinase 1 like (PDIK1L) (Figure 1). BOVINE

Table 2 Additive genetic variance $\left(\sigma_{A}^{2}\right)$, heritability $\left(h^{2}\right)$ for $\mathrm{Ca}, \mathrm{Cu}, \mathrm{Fe}, \mathrm{K}, \mathrm{Mg}, \mathrm{Mn}, \mathrm{Na}, \mathrm{P}, \mathrm{Se}$, and $\mathrm{Zn}$ in both the Danish Holstein and Danish Jersey

\begin{tabular}{lllll}
\hline Trait & $\mathbf{D H} \boldsymbol{\sigma}_{\mathbf{A}}^{\mathbf{2}}$ & $\mathbf{D H} \mathbf{h}^{\mathbf{2}}$ & $\mathbf{D J} \boldsymbol{\sigma}_{\mathbf{A}}^{\mathbf{2}}$ & $\mathbf{D} \mathbf{~ h}^{\mathbf{2}}$ \\
\hline $\mathrm{Ca}$ & 10278.18 & $0.72(0.36)$ & 13017.58 & $0.63(0.31)$ \\
$\mathrm{K}$ & $\mathrm{NC}$ & $\mathrm{N} C^{1}$ & 3125.03 & $0.32(0.21)$ \\
$\mathrm{Na}$ & $\mathrm{NC}^{1}$ & $\mathrm{~N} C^{1}$ & 1406.43 & $0.20(0.19)$ \\
$\mathrm{P}$ & 2547.80 & $0.46(0.25)$ & 2260.37 & $0.29(0.21)$ \\
$\mathrm{Mg}$ & 7.13 & $0.08(0.21)$ & 94.91 & $0.57(0.25)$ \\
$\mathrm{Cu}$ & $5.31 \mathrm{E}-05$ & $0.28(0.25)$ & $\mathrm{NC}^{1}$ & $\mathrm{NC}$ \\
$\mathrm{Fe}$ & $2.61 \mathrm{E}-07$ & $1.91 \mathrm{E}-4(0.22)$ & $4.02 \mathrm{E}-4$ & $0.15(0.19)$ \\
$\mathrm{Mn}$ & $3.05 \mathrm{E}-06$ & $0.13(0.17)$ & $\mathrm{NC}$ & $\mathrm{NC}$ \\
$\mathrm{Se}$ & $1.99 \mathrm{E}-07$ & $0.10(0.19)$ & $4.73 \mathrm{E}-07$ & $0.20(0.14)$ \\
$\mathrm{Zn}$ & 0.19 & $0.49(0.24)$ & 0.33 & $0.57(0.22)$ \\
\hline
\end{tabular}

(SE of the estimates in parenthesis).

${ }^{1} \mathrm{NC}$ : The model is not converging due to the fact that the genetic variance component goes to zero.
HD0200037025 is located in a LD block (BOVINEHD02 00037022 - BOVINEHD0200037028). The gene PDIK1L was the only gene located in this LD block.

\section{Danish Jersey}

In total 787 significant SNP markers were detected for $\mathrm{Ca}$ (44), Fe (43), K (498), Na (4), Mg (1), P (94) and Zn (3) (Additional file 3: Table S3).

For Ca SNP markers were detected on BTA14. For Fe a QTL was detected on BTA2, and the most significant SNP marker $\left(\right.$ BOVINEHD0200029849) had a $-\log _{10}(\mathrm{P}$-value $)=$ 10.81 and explained $4 \%$ of the total variance. The most significant marker was located in an LD block from BOVINEHD0200029809 - BOVINEHD0200029858. For K a QTL was detected on BTA6 with the most significant SNP marker was HAPMAP23226-BTA-159656 (46,599,570 bp) which had a $-\log _{10}(\mathrm{P}$-value $)=11.39$ and explained $10.4 \%$ of the total variation (Figure 2). HAPMAP23226-BTA159656 was located in a LD block from BOVINEHD0600012674 - BOVINEHD0600012692. There were no genes located in this LD block. For P a QTL was detected on BTA1 where the most significant SNP marker was BOVINEHD0100041584 at 144,353,573 bp with a $\log _{10}(\mathrm{P}$-value $)=8.79$ and explained $7.8 \%$ of the total variation. The most significant marker is located in a large $\mathrm{LD}$ block (BOVINEHD0100041525 - BOVINEHD0100041638). Within this LD block six genes were located: trefoil factor (TFF1), trefoil factor 2 (TFF2), transmembrane protease, serene 3 (TMPRSS3), ubiquitin-associated and SH3 domaincontaining protein A (UBASH3A), radial spoke head 1 homolog (Chlamydomonas) (RSPH1, and solute carrier family 37 (glucose-6-phosphate transporter), member 1 (SLC37A1).

\section{Overlapping SNPs}

Comparing the list of significant markers between $\mathrm{DH}$ and DJ revealed that the SNP ARS-BFGL-NGS-4939 was in common between these two breeds for $\mathrm{Zn}$. This SNP marker is closely linked to the DGAT1 gene. Even though we found significant SNP markers on BTA14 in both DH and DJ for $\mathrm{Ca}$, and Fe these significant SNPs did not overlap.

\section{Discussion}

In this study a genetic analysis was performed for the mineral content in bovine milk. This knowledge is important to evaluate the possibilities to change the mineral content in the milk by selective breeding.

\section{Mineral concentration}

The mineral concentration in the milk varied between $\mathrm{DH}$ and DJ, with DJ having a higher milk mineral concentration; however, the CV was comparable between the two breeds. Gaucheron [10] stated that milk mineral content is 


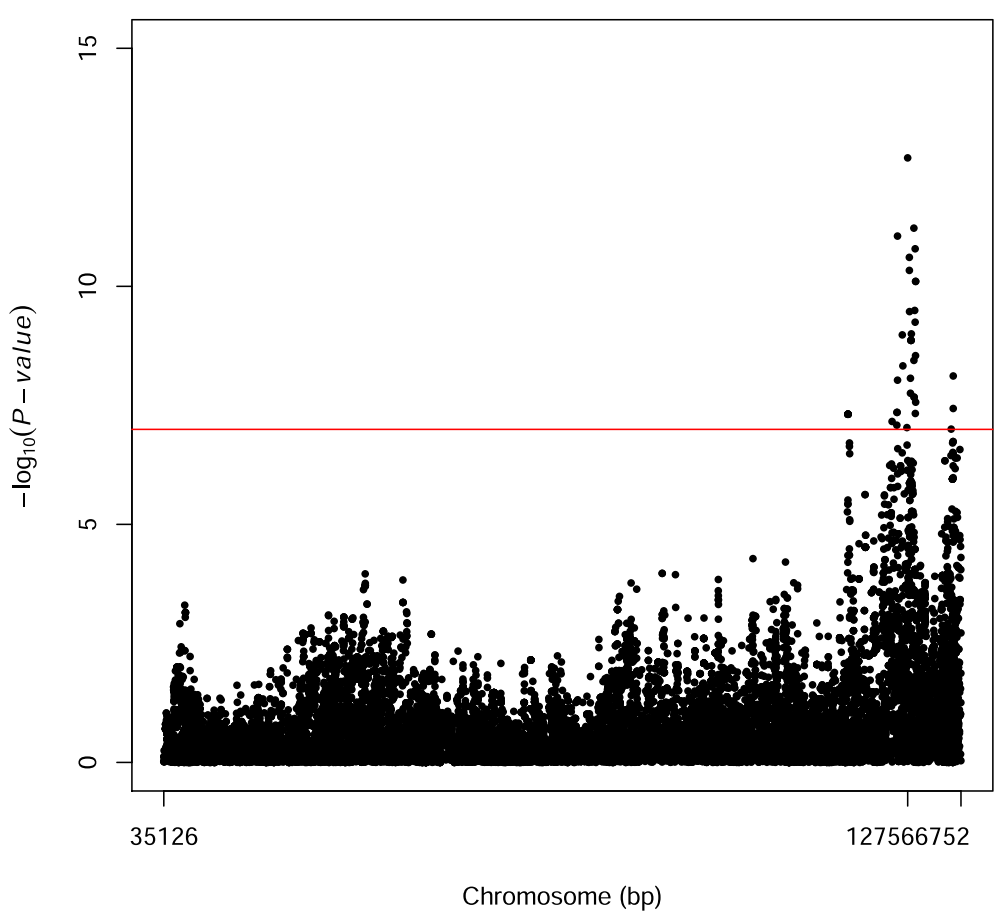

Figure 1 Manhattan plot of a GWAS on BTA02 for Zn for the Danish Holstein. The Y-axes show - $\log _{10}(\mathrm{P}$-value) of single-marker associations tests. The $X$-axes show marker positions in base-pairs. Red horizontal line is the significance threshold at FDR $<0.10$.

relatively constant however the present study showed that there is substantial variation for the different minerals in bovine milk. This is in line with previous results showing considerable variation in milk mineral content from Swedish and Danish herds due to primarily season, but also to breed [1,2]. Results found by van Hulzen et al. [11] also showed considerable variation for mineral content in milk of Dutch Holstein-Friesian cows caused by genetic and/or environmental and nutritional variation. In line with Bijl et al. [22], we found a relatively strong correlation between $\mathrm{Ca}, \mathrm{Mg}$ and $\mathrm{P}$ and protein, which is likely to contribute to the higher contents of these minerals in Jersey milk, as shown in the present study. This relationship is due to the association of these minerals with the casein micelle, which is also known to be of utmost importance for casein micelle stability $[9,10]$. Thereby their concentrations also affect the technological properties of the milk and lower $\mathrm{Ca}$ levels (and to some extent lower levels of $\mathrm{P}$ and $\mathrm{Mg}$ ) have been associated with poor or non-coagulating milk [23-25]. Milk contents of $\mathrm{Cu}, \mathrm{Fe}, \mathrm{Mn}, \mathrm{Se}$ and $\mathrm{Zn}$ further tended to be higher in DJ as compared to DH, which is in accordance with Hermansen et al. [1]. The $\mathrm{Cu}$ concentration in milk is known to vary between cows and with diet and level of mineral supplementation [26]. Previously it has been shown that the $\mathrm{Cu}$ concentration plays an important role in the spontaneous development of oxidative off-flavor of the milk $[27,28]$. The mineral contents reported here were based on skimmed milk, which could have affected the reported levels, as small amounts may be associated with the milk fat fraction. For instance phospholipids in the milk fat globule membrane would not have been included, which will have an effect on the milk P level as compared to earlier studies on full milk [1,2].

\section{Heritability}

In this study the heritabilities were estimated for ten different minerals in two different cattle breeds. High heritabilities were found for $\mathrm{Ca}$ and $\mathrm{Zn}$ in both $\mathrm{DH}$ and DJ. For the other minerals determined the results were less consistent, i.e. a high heritability was detected in only one of the two breeds analyzed (K (0.32), Mg (0.57) (DJ) and P (0.46) $(\mathrm{DH})$ ). Even though the standard errors are relatively large in our study, the results are in general in agreement with the heritability estimates presented by van Hulzen et al. [11]. They also found high heritabilities for $\mathrm{Ca}(0.57)$ and Zn (0.41) in first parity Dutch Holstein-Friesian cows, but also for $\mathrm{Mg}(0.60), \mathrm{K}(0.46)$ and P (0.62) [11].

\section{Screening mineral content in milk samples at large scale} The results of our study and the study of van Hulzen et al. [11] indicated that there is genetic variation for some of the minerals. This would open up the possibility to select 


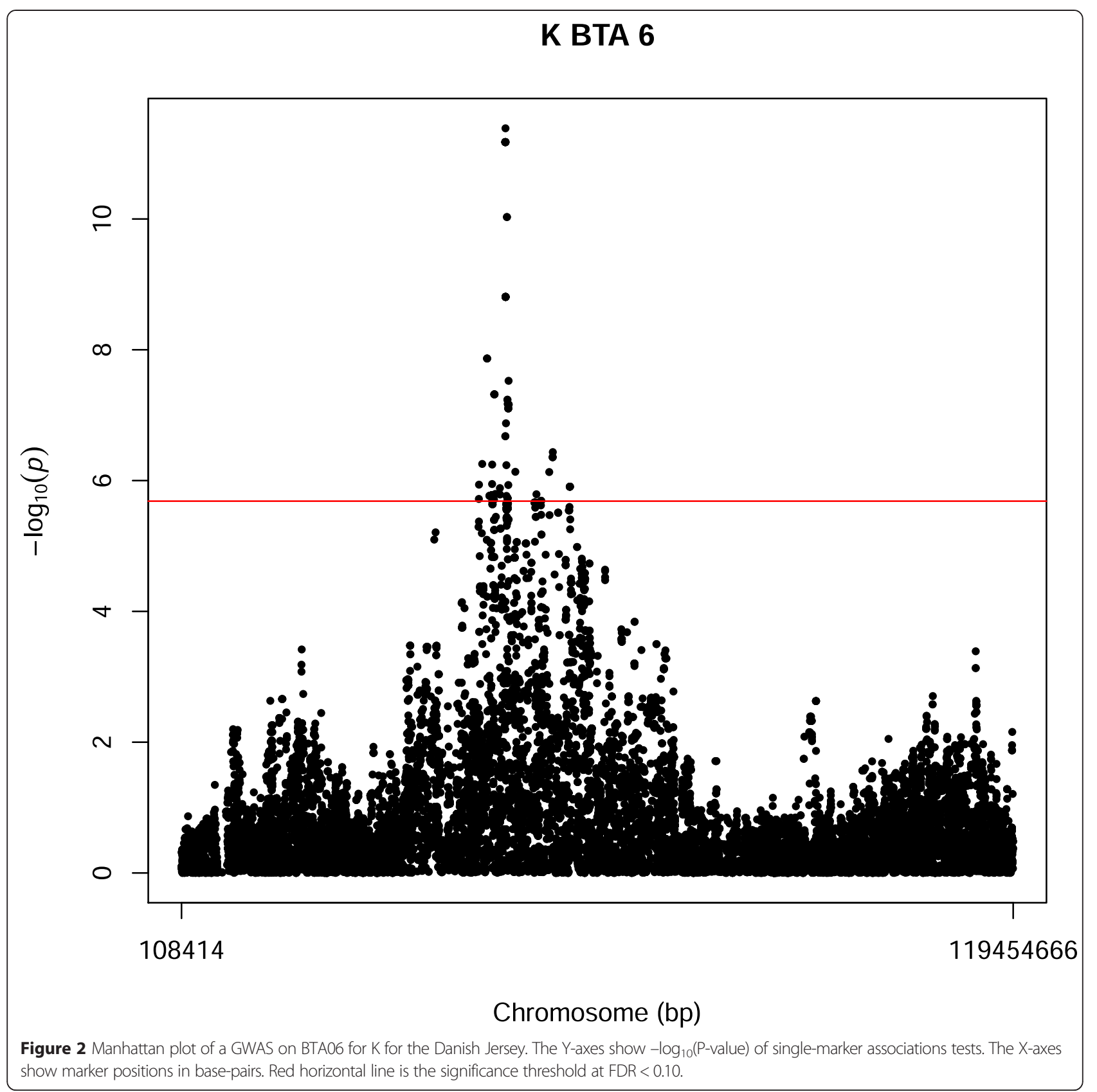

genetically for specific minerals in the milk. However the methods used to quantify the mineral content in dairy milk are labor intensive and expensive, and are therefore not suited to be implemented for large scale screening of milk samples from the milk control system. In the routine milk laboratories mid infra red spectroscopy has been implemented to measure fat and protein in the milk. Soyeurt et al. [29] investigated the possibility to estimate the mineral concentration in the milk based on infra red. They could develop and implement prediction models for $\mathrm{P}$ and $\mathrm{Ca}$ [29], but the development of prediction models for other minerals was more difficult (e.g. Mg, $\mathrm{Na}$ ) or impossible in case of K [29].

\section{QTL and genes for mineral content}

To our knowledge this is the first study to report GWAS results on the mineral content in milk. As the number of samples per population is relatively small, it is expected that only those QTL with large effect are detected. First we will focus on those QTL detected for minerals with a high heritability in one of the cattle breeds ( $\mathrm{Zn}$ and P), and then on those QTL 
detected for minerals with an intermediate heritability in one of the cattle breeds $(\mathrm{K}$ and $\mathrm{Cu})$.

\section{$\mathrm{Zn}$}

For $\mathrm{Zn}$ we detected a QTL in DH on BTA2 with the most significant SNP assigned to the gene (PDIK1L) (Figure 1). $P D I K 1 L$ is involved in biological processes like protein serine/threonine kinase activity, ATP binding and protein phosphorylation, i.e. introducing phosphate group to a protein (http://www.uniprot.org/uniprot/Q8N165). Phosphorylation of the (casein) proteins in the milk influences the stability of the casein micelle in the milk. Even though it is not known how this gene plays a role in the regulation of the $\mathrm{Zn}$ concentration in the milk at this stage, PDIK1L could be considered as a candidate gene.

A SNP marker close to DGAT was among the significant markers for $\mathrm{Zn}$ in both DH and DJ. How DGAT is involved in the $\mathrm{Zn}$ concentration in milk is at this stage unknown, however it has been shown that low de novo milk fat diet can significantly increase plasma $\mathrm{Zn}$ and milk $\mathrm{Zn}$ content, whereas dietary $\mathrm{Zn}$ level in itself did not influence $\mathrm{Zn}$ concentration in milk or plasma. This indicates that the transfer of fat from diet to milk might facilitate transfer of $\mathrm{Zn}$ from diet to milk [30].

$P$

In this study total $\mathrm{P}$ is measured including the bound $\mathrm{P}$. However we are using skimmed milk, which could explain the relative low levels of $\mathrm{P}$ in the milk samples compared to the literature [11]. The most significant marker (BOVINEHD0100041584) for P is located in a LD block containing 6 genes (TFF1, TFF2, UBASH3A, RSPH1 and SLC37A1). Based on the physical map position of BOVINEHD0100041584 and on the biological descriptions of the genes in the LD block, SLC37A1 is a good candidate gene. BOVINEHD0100041584 is located $10 \mathrm{~kb}$ downstream SLC37A1. In human SLC37A1 is involved in the transport of glucose-6-phoshate and plays an important role in the blood glucose homeostasis [31]. More specifically SLC37A1 showed phosphate linked glucose-6phoshate antiporter activity. SLC37A1 is part of the SLC37 family. The SLC37 family is a group of genes involved in the translocation of glucose-6-phoshate from the cytoplasm into the lumen of the ER. There glucose-6-phoshate is hydrolyzed into glucose and P. [31].

\section{$\mathrm{K}$}

Cohen-Zinder et al. [32] identified $A B C G 2$ at 37.4 $\mathrm{Mb}$ on BTA6. This gene has a major effect on milk yield and milk composition [32]. The most significant SNP marker for $\mathrm{K}$ is located around $46.6 \mathrm{Mb}$ (Figure 2), indicating that there is little or no overlap with $A B C G 2$.
$\mathrm{Cu}$

The $\mathrm{Cu}$ concentration in the milk varies between cows and depends on the diet and level of mineral supplementation [26]. Previously it has been shown that the $\mathrm{Cu}$ concentration plays an important role in the spontaneous development of oxidative off-flavor of the milk [27]. QTL regulating the $\mathrm{Cu}$ concentration in the milk may be of interest to reduce or increase the $\mathrm{Cu}$ concentration by genetics. Morris et al. [33] had detected QTL for $\mathrm{Cu}$ on BTA3, BTA5 and BTA13. These chromosomes were also among our results for $\mathrm{Cu}$ content in the milk in DH. A closer look showed however that these QTL [33] did not show overlap with the significant markers for $\mathrm{Cu}$ content in milk detected in our study. With regard to the development of oxidative offflavor in the milk the QTL on BTA14 for $\mathrm{Cu}$ is interesting. The significant SNP markers for $\mathrm{Cu}$ content in the milk are in LD with DGAT1 (data not shown) i.e. the LD block was based on the HD SNP markers covering the physical map position of DGAT1. Juhlin et al. [28] showed that DGAT1 polymorphisms together with the FA composition and $\mathrm{Cu}$ concentration were risk factors for the development of spontaneous oxidized flavor. In their study they tested the influence of DGAT1 on different fatty acid groups, however not on the $\mathrm{Cu}$ concentration in the milk. Our results suggest that the DGAT1 polymorphism may also influence the $\mathrm{Cu}$ concentration in the milk.

\section{Conclusion}

Profound differences in mineral concentration in the milk between DH and DJ were identified with a generally higher mineral concentration in milk from DJ. High heritability estimates were found for $\mathrm{Ca}$ and $\mathrm{Zn}$ in both $\mathrm{DH}$ and DJ. The GWAS identified QTL in both DH and DJ. A QTL on BTA14 for $\mathrm{Ca}$ and $\mathrm{Zn}$ was identified in both DH and DJ. However, the majority of the QTL identified were breed specific. The relatively high heritability estimates for content of several bovine milk minerals open up the possibility of elevating milk mineral content by genetic selection.

\section{Availability of supporting data}

No new SNPs were discovered in this manuscript. The SNPs used in this manuscript are from the Illumina Bovine HD SNP array: http://res.illumina.com/documents/ products/datasheets/datasheet_bovinehd.pdf. Names and location of these SNPs can be found at: http://support.illumina.com/downloads.html. Assigning the SNPs to genes was based on the publicly available bovine genome assembly: ftp://ftp.cbcb.umd.edu/pub/data/assembly/ Bos_taurus/Bos_taurus_UMD_3.1/annotation/UMD3.1.gff.gz. 


\section{Additional files}

Additional file 1: Table S1. Phenotypic correlation of between milk production traits and the mineral content of the milk. Above the diagonal the phenotypic correlation for the Danish Holstein and Danish Jersey breeds. Below the diagonal the standard error.

Additional file 2: Table S2. Significant SNP associated to Mineral traits in the Danish Holstein. A genome wide association scan was performed on the Danish Holstein cattle for detailed mineral composition. SNPS were considered significant at FDR $<0.10$.

Additional file 3: Table S3. Significant SNP associated to Mineral traits in the Danish Jersey. A genome wide association scan was performed on the Danish Jersey cattle for detailed mineral composition. SNPs were considered significant at FDR $<0.10$.

\section{Competing interest}

The authors declare that they have no competing interests.

\section{Authors' contributions}

BB processed the genotypes, performed the genetic analysis, and wrote the manuscript. NAP collected the milk samples and contributed to the discussion of the results. LBL contributed to the planning, sampling and discussion of the results. JS performed the analysis of the minerals in the milk and contributed to the discussion of the results. All authors contributed to the manuscript and approved the final version of the manuscript.

\section{Acknowledgements}

This study is part of the Danish-Swedish Milk Genomics Initiative (www.milkgenomics.dk) supported by the Danish Agency for Science, Technology and Innovation, Danish Cattle Federation, Aarhus University and Arla Foods amba (Viby J, Denmark), as well as part of the "Phenotypic and genetic markers for specific milk quality parameters" of the Milk Levy Fund, Denmark (2011-2013).

\section{Author details}

'Aarhus University, Center for Quantitative Genetics and Genomics, Department of Molecular Biology and Genetics, Blichers Allé 20, P.O. Box 50 DK-8830 Tjele, Denmark. ²Aarhus University, Department of Food Science, Blichers Allé 20, P.O. Box 50 DK-8830 Tjele, Denmark. ${ }^{3}$ Aarhus University, Department of Animal Science, Blichers Allé 20, P.O. Box 50DK-8830 Tjele, Denmark.

\section{Received: 27 February 2015 Accepted: 27 April 2015}

Published online: 21 May 2015

\section{References}

1. Hermansen JE, Badsberg JH, Kristensen T, Gundersen V. major and trace elements in organically and conventionally produced milk. J Dairy Res. 2005;72:362-8

2. Lindmark-Månsson $H$, Fondén $R$, Pettersson HE. Composition of Swedish dairy milk. Int Dairy J. 2003;13:409-25.

3. Cashman KD. Milk minerals (including trace elements) and bone health. Int Dairy J. 2006;16:1389-98.

4. Haug A, Høstmark AT, Harstad OM. Bovine milk in human nutrition-a review. Lipids Health Dis. 2007;6:25

5. Overton TR, Yasui T. Practical applications of trace minerals for dairy cattle. J Anim Sci. 2014;92:416-26.

6. Jelen P, Lutz S. Functional milk and dairy products. In: Mazza G, Shi J, Le Maguer M, editors. Pages 357-380 in Functional Foods: Biochemical and Processing Aspects Vol. 1. Boca Raton, FL: CRC Press; 1998.

7. Lönnerdahl B, Keen CL, Hurley LS. Iron, copper, zinc and manganese in milk. Ann Rev Nutr. 1981;1:149-74.

8. Tsioulpas A, Lewis MJ, Grandison AS. Effect of minerals on casein micelle stability of cows' milk. J Dairy Res. 2007;74:167-73.

9. Deeth HC, Lewis MJ. Practical consequences of calcium addition to and removal from milk and dairy products. Int J Dairy Technol. 2015;68(1):1-10.

10. Gaucheron F. The minerals of milk. Reprod Nutr Dev. 2005;45:473-83.

11. van Hulzen KJE, Sprong RC, van der Meer R, van Arendonk JAM. Genetic and nongenetic variation in concentration of selenium, calcium, potassium, zinc, magnesium, and phosphorus in milk of Dutch Holstein-Friesian cows. J Dairy Sci. 2009;92:5754-9.

12. Poulsen NA, Gustavsson F, Glantz M, Paulsson M, Larsen LB, Larsen MK The influence of feed and herd on fatty acid composition in 3 dairy breeds (Danish Holstein, Danish Jersey, and Swedish Red). J Dairy Sci. 2012;95:6362-71.

13. Cava-Montesinos P, Cervera ML, Pastor A, de la Guardia M. Room temperature acid sonication ICP-MS multielemental analysis of milk. Analytica Chimica Acta. 2005;531:111-23.

14. Buitenhuis AJ, Sundekilde UK, Poulsen NA, Bertram HC, Larsen LB, Sørensen $P$. Estimation of genetic parameters and detection of quantitative trait loci for metabolites in Danish Holstein milk. J Dairy Sci. 2013;96:3285-95.

15. Van Tassell CP, Smith TPL, Matukumalli LK, Taylor JF, Schnabel RD, Lawley $C T$, et al. SNP discovery and allele frequency estimation by deep sequencing of reduced representation libraries. Nature Methods. 2008;5:247-52.

16. Teo YY, Inouye M, Small KS, Gwilliam R, Deloukas P, Kwiatkowski DP, et al. A genotype calling algorithm for the Illumina BeadArray platform. Bioinformatics. 2007:23:2741-6.

17. Liu $Y$, Qin $X$, Song $X Z$, Jiang $H$, Shen $Y$, Durbin $K$, et al. Bos taurus genome assembly. BMC Genomics. 2009:10:180.

18. VanRaden PM. Efficient methods to compute genomic predictions. J Dairy Sci. 2008;91:4414-23

19. Madsen $P$, Jensen J: An user's guide to DMU. A package for analysing multivariate mixed models. 2007. Version 6, release 4.7. available at http:// dmu.agrsci.dk.

20. Yang J, Benyamin B, McEvoy BP, Gordon S, Henders AK, Nyholt DR, et al. Common SNPs explain a large proportion of the heritability for human height. Nature Genet. 2010;42:565-9.

21. Barrett JC, Fry B, Maller J, Daly MJ. Haploview: analysis and visualization of LD and haplotype maps. Bioinformatics. 2005;21(2):263-5.

22. Bijl E, van Valenberg HJF, Huppertz T, van Hooijdonk ACM. Protein, casein and micellar salts in milk: Current content and historical perspectives. J Dairy Sci. 2013;96:5455-64.

23. Hallén $E$, Lunden A, Tyriseva A-M, Westerlind M, Andren A. Composition of poorly and non-coagulating bovine milk and effect of calcium addition. J Dairy Res. 2010:77:398-403.

24. Jensen HB, Holland JW, Poulsen NA, Larsen LB. Milk protein variants and isoforms identified in bovine milk representing extremes in coagulation properties. J Dairy Sci. 2012;95:2891-903.

25. Jensen HB, Poulsen NA, Andersen KK, Hammershøj M, Poulsen HD, Larsen LB. Distinct composition of bovine milk from Jersey and Holstein-Friesian cows with good, poor, or noncoagulation properties as reflected in protein genetic variants and isoforms. J Dairy Sci. 2012;95:6905-17.

26. Dunkley WL, Franke AA, Robb J, Ronning M. Influence of dietary copper and ethylenediaminetetraacetate on copper concentration and oxidative stability of milk. J Dairy Sci. 1968;51:863-6.

27. Juhlin J, Fikse F, Lundén A, Pickova J, Agenäs S. Relative impact of alpha-tocopherol, copper and fatty acid composition on the occurrence of oxidized milk flavour. J Dairy Res. 2010;77:302-9.

28. Juhlin J, Fikse WF, Pickova J, Lundén A. Association of DGAT1 genotype, fatty acid composition, and concentration of copper in milk with spontaneous oxidized flavor. J Dairy Sci. 2012;95:4610-7.

29. Soyeurt H, Bruwier D, Romnee JM, Gengler N, Bertozzi C, Veselko D, et al. Potential estimation of major mineral contents in cow milk using midinfrared spectrometry. J Dairy Sci. 2009;92:2444-54.

30. Wiking $L$, Larsen $T$, Sehested J. Transfer of dietary zinc and fat to milkevaluation of milk fat quality, milk fat precursors, and mastitis indicators. J Dairy Sci. 2008:91:1544-51.

31. Pan CJ, Chen SY, Jun HS, Lin SR, Mansfield BC, Chou JY. SLC37A1 and SLC37A2 are phosphate-linked, glucose-6-phosphate antiporters. PLoS One. 2011;6, e23157.

32. Cohen-Zinder M, Seroussi E, Larkin DM, Loor JJ, Everts-van der Wind A, Lee $\mathrm{JH}$. Identification of a missense mutation in the bovine ABCG2 gene with a major effect on the QTL on chromosome 6 affecting milk yield and composition in Holstein cattle. Genome Res. 2005;15:936-44.

33. Morris CA, Bottema CD, Cullen NG, Hickey SM, Knowles SO, Pitchford WS Effects of quantitative trait loci and the myostatin locus on trace and macro elements (minerals) in bovine liver, muscle and kidney. Anim Genet. 2013:44:361-8. 